\title{
RISK ASSESSMENT AND MANAGEMENT DURING DEVELOPMENT OF GAS TURBINE ENGINE SUB-SYSTEMS
}

\author{
Parthasarathi Hans ${ }^{1}$, Ramachandra S, Srinivasamurthy PN, Jha BK \\ Gas Turbine Research Establishment \\ Bangalore, India \\ E-mail: hans@gtre.drdo.in
}

\begin{abstract}
Enhancement of complexity is associated with the evolution of any system, and risk escalates with complexity. Hence, any development process, including that of a gas turbine engine, is essentially a process of assessment and management of risk. Gas turbines, especially those used in aeronautical applications, are highly complex systems that involve several complex modules and sub-systems, including compressor, combustor, turbine, fuel system, engine gearbox, etc. This study focuses on engine gearbox, which is a very complex sub-system itself, involving a high level of developmental risk. The main functions of this gearbox are to transmit power from starter to engine main shaft during engine start-up and drive a host of accessories by extracting power from the engine during its operation. The gearbox supports and drives each accessory at a specific speed and direction of rotation. One of its important structural requirements is to be free from any destructive vibration throughout its operational range. It is also required to function in various altitude and attitude conditions, satisfying arduous endurance requirements. Further, like any other airborne system, the gearbox should also be designed to a strict weight budget. These conflicting requirements pose considerable challenges to the designer and call for a careful decision-making process. To solve this complex problem, it was decomposed into smaller sub-problems using Analytic Hierarchy Process (AHP). Various design alternatives were considered; their capability of meeting various design criteria and the risk involved were studied before arriving at a decision. Furthermore, it is apparent that these risks need to be monitored and managed regularly during the course of design.
\end{abstract}

Keywords: gearbox, transmission, risk management

1

Corresponding Author: hans@gtre.drdo.in, Ph: +91 80 25040417, Fax: +91 80 